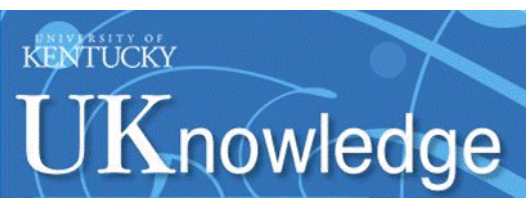

University of Kentucky

UKnowledge

$5-2016$

\title{
African American Female Offender's Use of Alternative and Traditional Health Services After Re-Entry: Examining the Behavioral Model for Vulnerable Populations
}

\author{
Carrie B. Oser \\ University of Kentucky, carrie.oser@uky.edu \\ Amanda M. Bunting \\ University of Kentucky, amanda.bunting@uky.edu \\ Erin L. Pullen \\ University of Kentucky, erinpullen@uky.edu \\ Danelle Stevens-Watkins \\ University of Kentucky, d.stevenswatkins@uky.edu
}

Follow this and additional works at: https://uknowledge.uky.edu/sociology_facpub

Part of the Counseling Psychology Commons, Inequality and Stratification Commons, Race and Ethnicity Commons, and the Substance Abuse and Addiction Commons

Right click to open a feedback form in a new tab to let us know how this document benefits you.

\section{Repository Citation}

Oser, Carrie B.; Bunting, Amanda M.; Pullen, Erin L.; and Stevens-Watkins, Danelle, "African American Female Offender's Use of Alternative and Traditional Health Services After Re-Entry: Examining the Behavioral Model for Vulnerable Populations" (2016). Sociology Faculty Publications. 15. https://uknowledge.uky.edu/sociology_facpub/15

This Article is brought to you for free and open access by the Sociology at UKnowledge. It has been accepted for inclusion in Sociology Faculty Publications by an authorized administrator of UKnowledge. For more information, please contact UKnowledge@lsv.uky.edu. 


\section{African American Female Offender's Use of Alternative and Traditional Health Services After Re-Entry: Examining the Behavioral Model for Vulnerable Populations}

Digital Object Identifier (DOI)

https://doi.org/10.1353/hpu.2016.0052

Notes/Citation Information

Published in Journal of Health Care for the Poor and Underserved, v. 27, no. 2 supplement, p. 120-148.

Copyright $@ 2015$ Meharry Medical College

The copyright holder has granted the permission for posting the article here.

The document available for download is the authors' post-peer-review final draft of the article. 


\title{
African American Female Offender's Use of Alternative and Traditional Health Services After Re-Entry: Examining the Behavioral Model for Vulnerable Populations
}

\author{
Carrie B. Oser, $\mathrm{PhD}^{1}$, Amanda M. Bunting, $\mathrm{MA}^{2}$, Erin Pullen, $\mathrm{PhD}^{3}$, and Danelle Stevens- \\ Watkins, $\mathrm{PhD}^{4}$ \\ Carrie B. Oser: carrie.oser@uky.edu; Amanda M. Bunting: amanda.bunting@uky.edu; Erin Pullen: erinpullen@gmail.com; \\ Danelle Stevens-Watkins: d.stevenswatkins@uky.edu \\ 11531 Patterson Office Tower, Department of Sociology, Center on Drug \& Alcohol Research, \\ University of Kentucky, Lexington, Kentucky, 40506. Phone: 859-257-6890. Fax: 859-323-0272 \\ 21505 Patterson Office Tower, Department of Sociology, University of Kentucky, Lexington, \\ Kentucky, 40506. Phone: 859-257-6896. Fax: 859-323-0272 \\ ${ }^{3}$ Indiana University Network Science Institute, Bloomington, Indiana, 47405. Phone: \\ 231-878-8494. Fax: 812-855-0781
}

4245 Dickey Hall, Department of Educational, Counseling, and School Psychology, University of Kentucky, Lexington, Kentucky, 40506. Phone: 859-257-7889. Fax: 859-257-5662

\begin{abstract}
This is the first known study to use the Gelberg-Andersen Behavioral Model for Vulnerable Populations to predict African American women's use of three types of health services (alternative, hospitalization, and ambulatory) in the 18 months after release from prison. In the multivariate models, the most robust predictors of all three types of service utilization were in the vulnerable theoretical domains. Alternative health services were predicted by ethnic community membership, higher religiosity, and HIV/HCV. Hospitalizations were predicted by the lack of barriers to health care and disability. Ambulatory office visits were predicted by more experiences of gendered racism, a greater number of physical health problems, and HIV/HCV. Findings highlight the importance of cultural factors and HIV/HCV in obtaining both alternative and formal health care during community re-entry. Clinicians and policy makers should consider the salient role that the vulnerable domain plays in offender's accessing health services.
\end{abstract}

\section{Keywords}

Health Services; Vulnerable Populations; African Americans; Women; Prisoners

High rates of incarceration in the United States have led to substantial increases in the amount of women serving time behind bars. ${ }^{1}$ The increase is disproportionate for African American women, with rates of 115 per 100,000 residents compared with 49 for White women and 64 compared with Hispanic women. ${ }^{2}$ Incarcerated African American women are 
considered a "vulnerable population" as defined by Aday ${ }^{3}$ because they have a greater relative risk of poor health, due to differential exposure of risk factors, compared with the general population.

African American women possess limited access to resources to address their health conditions due to intersecting oppressions of race, class, and gender that may be further compounded by involvement with the criminal justice system. These individual and societal factors can be considered in the context of Gelberg, Andersen, and Leake's Behavioral Model for Vulnerable Populations ${ }^{4}$ to determine predictors of health service utilization among this vulnerable population. Due to limited financial resources and the prominent influence of kinship and religion in the African American community, African American women may seek out alternative sources of health care from family and religious counselors. ${ }^{5}$ Therefore, the overall purpose of this study is to use the Behavioral Model for Vulnerable Populations to predict African American women's use of three types of health services (alternative, hospitalization, and ambulatory) in the 18 months after release from prison.

\section{Re-entering African American women: A vulnerable population}

The Behavioral Model for Vulnerable Populations has frequently been applied to examine health service utilization among homeless persons $s^{4,6-10}$ and although there is a high concordance between incarceration status and homelessness, this study seeks to offer insight on the most vulnerable timeframe when persons are transitioning back into the community. Previous literature has suggested that the model may be applicable to persons under criminal justice supervision given similar issues of vulnerability that limit access to care. ${ }^{11,12}$ According to Aday, ${ }^{3}$ individuals with a combination of high risk statuses (e.g., low-income, female, and African American in the current study) are in a highly vulnerable health position. Further, incarcerated women are likely to experience multiple categories of vulnerability including physical, psychological, and social health issues. ${ }^{3,13,14}$ Compared with the general population, prison and jail inmates are more likely to currently or ever have had a chronic health condition, specifically high rates of stroke-related problems, high blood pressure, diabetes, heart-related problems, asthma, cirrhosis of the liver, tuberculosis, hepatitis, and human immunodeficiency virus (HIV). ${ }^{13}$ Females and older prisoners are most affected by health problems with women experiencing high rates of comorbid substance use and mental health problems. ${ }^{14}$ Nationally, females in prison $(63 \%)$ were found to experience statistically significant higher rates of chronic conditions compared with incarcerated males $(50 \%) \cdot{ }^{13}$

According to the National Commission on Correctional Health Care ${ }^{15}$ health conditions are often poorly managed in prison or jail. In part, this may be attributed to correctional institutions incomplete adherence to national clinical guidelines, which may result in gaps in prevention, screening, and treatment that create financial burdens on re-entering offenders and their communities. Previously incarcerated individuals must cope with limited availability of health services, lack of health insurance, and insufficient post-release planning. ${ }^{16,17}$ Many individuals return to communities that already struggle with access to adequate health services and have considerable other health disparities. ${ }^{17,18}$ As such, these 
communities are further burdened as persons with high prevalence of HIV, other infectious diseases, and co-morbid health conditions return to the communities facing barriers to obtaining care. ${ }^{17,18}$

\section{Theoretical framework}

The Behavioral Model for Vulnerable Populations is an extension of the original Behavioral Model developed by Andersen and Newman ${ }^{19}$ and emerged as a result of Aday's ${ }^{3}$ framework addressing the specific needs of vulnerable populations. The model assists in identifying the determinants that lead an individual to use health care services. The three components of the model are (1) Predisposing characteristics that exist before an onset of illness (e.g., sociodemographic variables, health beliefs, and values); (2) Enabling factors that affect an individual's ability to secure health services in the community (e.g., personal, family, and community resources); and (3) Need characteristics including the actual health problems of the population(s). ${ }^{4,19}$ The three components of the model are further broken into traditional domains from the original model with the addition of vulnerable domains. The vulnerable domains were added to account for specific problems more frequently encountered by vulnerable populations that complicate their ability to obtain care. In this paper examining recently released African American women, variables are stratified in the domains identified in previous research when available, with additional measures included that are specifically relevant to marginalized African American populations (see Figure 1).

Predisposing traditional domain variables include demographics such as age, gender, or marital status as well as social structure variables including ethnicity or education. Previous research has found support for Predisposing traditional domains as predictive of health service utilization among vulnerable populations, including age, ${ }^{4,7,20-22}$ race, ${ }^{4,9,12}$ education, $4,7,22$ and marital status. ${ }^{12}$ Specifically, older age, more education, and being married are associated with increased access to care, while findings on race have been mixed. $4,7,9,12,20-22$

The Predisposing vulnerable domain may include variables such as involvement with the criminal justice system, sexual orientation, or victimization history. Among Predisposing vulnerable variables, a history of victimization, ${ }^{4,10}$ and incarceration history ${ }^{7,12}$ were found to be significantly related to decreased health service utilization. Other factors in the Predisposing vulnerable domain that are particularly relevant for re-entering African American women, but have yet to be examined are experiences of gendered racism as well as embeddedness in an ethnic community. It is predicted that these variables could impede seeking traditional health care because of the skepticism held by African Americans toward primarily White providers and institutions given adverse historical experiences (e.g., Tuskegee syphilis study) of scientific and institutional racism. ${ }^{23,24}$ However, such experiences may increase the use of alternative sources of health care. To date, current research using this theoretical framework has yet to examine religiosity as a predictor of health service utilization, though it has been identified as a potential reason for underutilization of traditional health services among African Americans. ${ }^{25}$ Research suggests that religion is important to African Americans, who also value the collective sense of self and connectedness to others. ${ }^{26-28}$ Therefore, religiosity may decrease the use of 
traditional health services, especially for the treatment of behavioral health problems. Some health problems (e.g., substance abuse or depression) may be viewed as spiritual problems in need of non-medical intervention within one's own community, rather than medical problems in need of traditional treatment. ${ }^{29}$ Alternatively, African American women may experience concern of disappointing their family or community by acknowledging such problems and pursue treatment outside the relative safety and privacy of one's own community. ${ }^{27}$

Enabling traditional factors operationalize resources through variables such as income, health insurance, and community health care barriers. Enabling vulnerable variables can include receipt of public benefits and disability status. Overall, research findings from studies focused on vulnerable populations indicate that Enabling variables increase the use of medical services. ${ }^{4,20,22,30}$ Having health insurance positively predicts health service utilization as well as recently seeing a physician or having a regular source of care. ${ }^{20,22,30}$ Limited research has examined how the number of self-reported barriers affect vulnerable populations. However, a study by Brubaker and colleagues ${ }^{6}$ revealed a paradoxical finding that fewer individual barriers were associated with decreased odds of accessing substance abuse services. Considering the underutilization of this measure in extant research, and its prior application to only substance abuse service among homeless adults, it remains underdeveloped as an Enabling traditional variable. Research on social support has resulted in mixed findings with some studies reporting no association with health service utilization. 4,9,22 A study of low-income African American women found that high levels of familial support decreased the use of preventative care, but social support from friends increased access to care. ${ }^{30}$

Among the Enabling vulnerable domain, public benefits - sometimes combined with receipt of social security disability insurance - has received mixed findings as a predictor of healthcare utilization. ${ }^{4,10,22}$ Another culturally relevant factor to African American women that may facilitate the use of health services is active coping. The concept of John Henryism Active Coping (JHAC) is rooted in the notion that economically disadvantaged African Americans need to overcome adversities via hard work and determination. ${ }^{31}$ However, research indicates that active coping results in adverse health outcomes for African American men. ${ }^{32}$ Though James ${ }^{32}$ suggested that gender was irrelevant in the study of active coping, the concept has primarily been examined in men. Existing research on active coping among African American women has demonstrated that it is associated with positive health outcomes. ${ }^{33,34}$ To date, no known research has examined active coping as a predictor of health service utilization.

Factors in the Need traditional domain may include both perceived and evaluated health problems warranting medical attention. Illness-level factors have been significantly associated with a variety of health services and have been operationalized in various ways such as one's overall self-rated health, the number of physical health problems, the presence of chronic health conditions, and the number of times seriously ill.4,11,12 In Gelberg, Andersen \& Leake's ${ }^{4}$ original research, persons with co-morbid conditions were found to access health services more frequently. Overall however, the Need traditional domain remains underutilized in applications to vulnerable populations. 
Vulnerable factors for the Need domain include health issues that are more prevalent in vulnerable populations such as mental health problems, substance use disorders, and infectious diseases like HIV. ${ }^{4}$ Previous research has indicated that Need variables are associated with increased use of health service utilization. ${ }^{4,6,9,12,20}$ Specifically, a history of mental health problems, ${ }^{9,10,12,21,22}$ substance use problems, ${ }^{12,21}$ and HIV status ${ }^{22}$ have been found to contribute to the likelihood of seeing a doctor among vulnerable populations. Sexually transmitted infections (STI's) and the Hepatitis C virus (HCV) may predict health care utilization similar to HIV status.

Previous applications of the Behavioral Model for Vulnerable Populations have operationalized health service utilization in a variety of ways including having seen a physician during a defined time period, $, 417,22$ having a regular source of care, ${ }^{17}$ not seeing a doctor when perceived as necessary, ${ }^{10}$ and using inpatient and outpatient mental health and/or substance use services. $., 9,12,21$ The current research seeks to expand upon previous literature by specifically examining three distinct types of health service utilization: alternative health services, overnight hospitalizations, and number of ambulatory office visits. While the distinction between overnight hospital visits and outpatient care is a substantial contribution to extant research, the addition of alternative health services is particularly relevant to the included population. African American communities are characterized as having extensive kinship networks, which provide a variety of resources. ${ }^{35-38}$ Moreover, prior research has indicated the importance of religion in the African American community and that highly spiritual or religious African Americans are more likely to relinquish their health decisions to a higher power, which may affect decision making such as accessing preventative care less frequently. ${ }^{25,30,39}$ At times, there may even be overlap between the use of health services from spiritual or religious counselors and family members. Therefore, the umbrella term of "alternative sources of care" was used to encompass both spiritual or religious counselors and family members as health care providers, due to its cultural relevance among African American women as a source of health care outside of the mainstream healthcare system. African American women, especially those with limited financial resources, may seek health care from these types of alternative sources.

\section{The present study}

Existing empirical research has linked a variety of variables from the Behavioral Model for Vulnerable Populations to health service utilization; however, mixed findings on specific vulnerable populations indicate that further research is necessary. The current study seeks to contribute to previous literature by examining two waves of data on a previously unexamined vulnerable population of African American women nearing re-entry, who are at the intersection of multiple disadvantaged statuses. Scholars have called for additional research on the adverse effects of incarceration on the health and well-being of African American women, as well as suggested the need for correctional policy changes to address this important public health concern. ${ }^{40-42}$ Further, exploration of both non-traditional and traditional health services (i.e., alternative health care use, overnight hospitalizations, and the number of ambulatory visits) provides a new application of the Behavioral Model for Vulnerable Populations tailored to a specific underserved and understudied group. The 
health status of soon-to-be-released inmates is a public health priority due to high rates of physical and mental health co-morbidities among a population released into predominantly disadvantaged communities. ${ }^{15,18,41,43,44}$ Examination of this population at a time of high health care need may provide insights to increasing access to care and improving overall health.

Good health is important for maintaining supportive social networks, stable housing, employment, and other essentials of a successful return to society, which reduces societal costs. ${ }^{15,16,18}$ Therefore the current research uses longitudinal data from African American women to (1) identify the prevalence of health problems as well as the barriers to health care both in the community and during incarceration; and (2) examine the use of the Behavioral Model for Vulnerable Populations to predict alternative health care use, overnight hospitalizations, and the number of ambulatory visits in the 18 months after release. Based on previous research, the hypotheses are four-fold. First, variables within the vulnerable strata of all three components of the theoretical model will be the most robust predictors of the use of all three types of health services utilization. Second, vulnerable domain variables will differentially predict the type of health care service. Culturally-specific variables in the vulnerable domains (e.g., religiosity, ethnic community membership) will increase the use of alternative services but decrease the use of traditional services. Moreover, variables in the vulnerable domain that contribute to African American women's disadvantaged status via increased health problems (e.g., disability, victimization) will increase the use of traditional health care. Third, the Predisposing and Enabling domains will be important in explaining the use of alternative and ambulatory office visits. Fourth, the Enabling and Need domains will be important predictors of overnight hospitalizations, as these are costly and invasive.

\section{Methods}

\section{Sample}

Data for this study were derived from a large federally supported project titled Black Women in the Study of Epidemics (B-WISE). The overall purpose of the B-WISE project was to examine health problems and health services utilization among drug using and non-drug using African American women across criminal justice status (i.e., women in prison, women on probation, and women not currently involved in the criminal justice system). A stratified sampling design was used to ensure approximately half of the sample was drug users and half of the sample was non-drug users. However, drug users are overrepresented in the prisoner sample due to the high prevalence of drug use in prisoner populations. ${ }^{14}$ This study focuses on two waves of data from the prison sample. While 243 African American women completed Wave 1 baseline interviews while incarcerated, 62 women were denied parole and not released during the study time-frame. The analyses are based on the 181 participants released from prison and thus, eligible for the Wave 2 data collection at 18-months postrelease.

Between 2008 and 2011, all African American eligible for release in the next 60 days from the three women's prisons in one southern state were invited to an information session ${ }^{\mathrm{i}}$. Eligibility criteria included the following: (1) self-identifying as an African American woman, (2) being at least 18 years of age, (3) speaking English, (4) willingness to 
participate, and (5) meeting the parole board or serving out within 60 days. After the information session, interview appointments were scheduled for African American women interested in participating in the study and meeting the eligibility criteria. Prior to data collection, informed consent was obtained.

All interviews were conducted by trained African American female interviewers in the prison visitation rooms using laptops programmed with Computer Assisted Personal Interviewing (CAPI) software. Prison staff members were not present for the interviews and no participant data was shared with the Department of Corrections. Participants were offered testing for the human immunodeficiency virus (HIV) and the Hepatitis C Virus (HCV) as part of the study protocol and all interviewers were state certified HIV interventionists. Preand post-test counseling for HIV and HCV were conducted by the interviewers in accordance with the CDC's rapid test counseling, testing, and referral protocols. ${ }^{45,46}$ It should be noted that participants could still participate in the study if they chose not to engage in the testing, however, all participants participated in HCV testing and only one participant declined HIV testing. The data collection process, including pre- and post-test counseling, lasted approximately two hours. Participants were compensated up to $\$ 40$ for participating in the Wave 1 data collection.

All participants who completed Wave 1 interviews were eligible for Wave 2 follow-up interviews upon community re-entry. Interviews were conducted 18-months after re-entry in private rooms in accessible public locations such as public libraries, on a university campus, or at a community-based organization. To ensure high follow-up rates, a wide array of participant locator information was collected at Wave 1 as well as every two months throughout the duration of the study. Systematic tracking efforts were also implemented (e.g., birthday card mailings, courthouse record searches, and use of social media such as a private B-WISE Facebook page). Participants were compensated $\$ 25$ for participating in the Wave 2 data collection, with a $\$ 10$ completion bonus. The prison sample follow-up rate at 18 -months post-release was $86 \%$. All B-WISE procedures were reviewed and approved by a University Institutional Review Board. To protect participants, a federal Certificate of Confidentiality was obtained from the National Institutes of Health due to the sensitive nature of the data collected.

\section{Measures}

Dependent variables-Three dependent variables measuring health services utilization after re-entry were of interest including alternative health care, hospitalizations, and ambulatory visits. All dependent variables were created using data from Wave 2. First,

\footnotetext{
i In an effort to shed light on prison characteristics that may impact barriers to correctional healthcare, additional details are provided on the three women's prisons in operation between 2008 and 2011. Prison A opened in 1938 and is a state-supported multi-custody facility with a population of averaging between 650-700 female inmates and employing approximately 220 staff. The annual daily cost per inmate is $\$ 77.29$ with an annual operating budget of $\$ 11.9$ million. Prison B is also a state-supported institution opened in 1977, which has both medium and minimum security status. It detains approximately 675-700 female inmates, with an average daily expenditure of $\$ 70.55$ and annual operating budget of $\$ 12.3$ million. Approximately 210 staff are employed at Prison B. Prison C, opened in 2005, was managed by Corrections Corporation of America (CCA) and employed approximately 200 staff. This private women's prison provided up to 656 beds for inmates with minimum, medium, or maximum security level status, about 450 of which were under contract from this southern state. No details could be located for Prison C on the size of the operating budget and the prison closed in 2012.
} 
participants were asked if they had received health care in the past 18 months from a spiritual or religious counselor (e.g., faith healer, root doctor, or spiritualist) or a family member (e.g., mother, grandmother, etc.). Responses were coded as $1=$ use of alternative health services and $0=$ no use of alternative health services ${ }^{\text {ii }}$. Second, participants were asked in the past 18 months, "How many times were you admitted to a hospital where you stayed overnight?" Responses were recoded into a dichotomous variable (1=overnight hospitalization, $0=$ no overnight hospitalization). The last dependent variable of interest, ambulatory care, was a count measure. Specifically, participants were asked the number of times they received treatment in an outpatient clinic or private physician's office in the 18 months after being released from prison.

Independent variables-All independent variables were derived from Wave 1. The Behavioral Model for Vulnerable Populations ${ }^{4}$ was used to categorize the independent variables into three components (Predisposing, Enabling, and Need), each of which includes both a traditional domain and a vulnerable domain. Described below is the operationalization of variables in each of the domains.

Predisposing traditional domain-This domain included age, measured in number of years, and the number of biological children under the age of 18. Dichotomous variables assessed if the participant was married, had a high school degree, and was employed either part time or full-time in the year prior to incarceration (1=yes, $0=$ no).

Predisposing vulnerable domain-Nine items are included in the Predisposing vulnerable domain. Dichotomous variables assessed if the participant identified as a sexual minority (1=gay or bisexual, $0=$ heterosexual), was homeless in the year prior to incarceration $(1=$ yes, $0=$ no), and was an active member in an organization or social group which included mostly members of their own ethnic group (1=active member of ethnic community, $0=$ not active member). ${ }^{47}$ Number of times incarcerated was a continuous variable. Religiosity was measured on a 4-point likert scale ranging from $0=$ not religious to $3=$ very religious. The three victimization measures were derived from the Global Appraisal of Individual Needs (GAIN) General Victimization Index (GVI) ${ }^{48}$ to measure if the participant had experienced any type of victimization as a child $(1=y e s, 0=$ no), had been physically victimized as an adult ( $1=$ yes, $0=$ no), or had been sexually victimized as an adult ( $1=$ yes, $0=$ no). The gendered racism scale was created using the 10 item Schedule of Sexist Events (SSE) ${ }^{49}$ and the 12 item Schedule of Racist Events (SRE) ${ }^{50}$ These two instruments asked participants about their experience of unfair treatment "because you are a woman" and "because you are Black," respectively. An example item on the SRE was "How many times have you been treated unfairly by your employers, bosses and supervisors because you are Black?" For theoretical and methodological reasons, such as difficulties attributing the cause of unfair treatment to one's race versus one's gender and multicollinearity between the sexist and racist event scales $(r=.55, p=.000)$, the SSE and SRE were combined into one scale. See Perry and colleagues ${ }^{51}$ for a detailed discussion on the rational and creation of the

\footnotetext{
ii Data on other alternative health services, such as the use of providers of eastern medicine, were included in the study; however, the infrequent use of these health services did not provide enough power to statistically model this relationship. The prevalence of the use of acupuncturist was $0.6 \%(\mathrm{n}=1)$ and no participants received health care from a naturopath or hypnotist.
} 
gendered racism scale. Items were measured on a 4-point likert scale and were summed so that higher scores indicated more experiences of gendered racism. The gendered racism scale had good internal reliability $(a=.90)$.

Enabling traditional domain-Two dichotomous measures asked if the participant had health insurance and had a usual doctor in year prior to incarceration ( $1=y e s, 0=n o)$. Annual household income in the year prior to incarceration was recoded to the midpoint and measured in tens of thousands of dollars. The Multidimensional Scale of Perceived Social Support (MSPSS) ${ }^{528}$ included 12 items measured on a 7-point likert scale to assess social support from family, friends, and/or a significant other. An example of an item from the scale was "My family really tries to help me." To create the mean scale, items were summed and divided by 12 . Higher scores on the MSPSS denoted more social support and the scale had strong internal reliability $(a=.91)$.

Participants were asked about barriers to health care in the year prior to incarceration as well as while incarcerated. For example, participants were asked "Are any of the following statements reasons why you didn't get health care or even an annual physical exam during the year before your incarceration?" Participants were provided with a list of 29 reasons for not obtaining health care and were asked to check all that apply. An "other, please specify" option was also offered. These questions were repeated to assess the barriers to prison health care and a list of 26 options was provided to participants. Due to low frequencies on several of items, the statements were grouped into nine barrier categories: did not want treatment, procrastination, cost, unfair treatment/discrimination, health care system, fear of diagnosis or clinical treatment, using drugs or absconding (community only), logistical life barriers (community only), and dissatisfaction with prison health care (prison only). It should be noted that two barrier categories were community-specific and one category was prisonspecific, while the remaining six categories could be barriers to health services utilization in both prison and/or in the community. The six categories were used to examine differences between community and prison health care barriers in the bivariate analyses. The multivariate models included a sum of the number of barriers to health care in the year prior to incarceration.

Enabling vulnerable domain-Participants were asked if they had received public benefits (e.g., food stamps, housing assistance, Medicaid, etc.) $(1=\mathrm{yes}, 0=$ no) or social security disability insurance (SSDI, $1=y e s, 0=n o$ ) in the year prior to incarceration. The John Henryism scale for active coping was created to measure an individual's ability to cope actively with difficult psychosocial and environmental stressors. ${ }^{32}$ The 12 items in the additive scale were measured on a 5-point likert scale. An example of the wording of an item was "In the past, even when things got really tough, I never lost sight of my goals."

Responses for the items in the scale were summed so that higher values indicated a higher predisposition to cope actively $(a=.79)$.

Need traditional domain-Two measures were included in this domain. First, participants were asked "During your current incarceration, has your health at any time limited the kind of activities you can do?" Participants could respond either $1=y e s$ or $0=$ no. Second, participants were asked if they had ever experienced any of the following 12 
physical health problems to create a count measure of the number of physical health problems: respiratory/breathing problems, muscle/bone problems, liver problems, high blood pressure, high cholesterol, heart attack or stroke, obesity, stomach or digestive problems, nervous system problems, skins problems, eye/ear/nose/throat problems, or any type of cancers.

Need vulnerable domain-This last domain of the theoretical model included four measures. Ever having injected drugs in one's lifetime was a dichotomous variable (1=yes, $0=$ no). Number of behavioral health problems was a count measure ranging from zero to four to assess if the participant had ever experienced alcohol problems, drug problems, mental health problems, and/or post-traumatic stress disorder. Participants were asked if they had ever been told they had a sexually transmitted infection (other than HIV) by a healthcare professional $(1=y e s, 0=$ no). As part of the B-WISE protocol, participants were tested for antibodies to HIV and HCV using the OraQuick ${ }^{\circledR}$ ADVANCE ${ }^{\text {TM }}$ Rapid HIV-1/2 Antibody Test and the Home Access Health Hepatitis C custom device blood test, respectively. A measure was created to assess if the participant had screened reactive for either HIV and/or HCV ( $1=$ yes, $0=$ no).

\section{Analytic plan}

Descriptive statistics and associations on all variables of interest were examined. The McNemar test was used to examine bivariate differences between African American women's barriers to health services in the year prior to incarceration and the use of health services in prison on six barrier categories (did not want treatment, procrastination, cost, unfair treatment or discrimination, health care system, and fear of diagnosis or clinical treatment) as well as if they had ever experienced any barrier. The barrier categories experienced in the community as compared with prison were significantly different if $\mathrm{p}<.05$. In addition, the percentage of participants that cited the community-specific barriers (i.e., using drugs or absconding and logistical life barriers) and the prison-specific barrier (i.e., dissatisfaction with prison health care) were explored.

Due to the relatively small sample size for the multivariate analyses, variable selection techniques were used. Specifically, only independent variables which were significantly associated at the .05 level or below with one of the dependent variables in a correlation matrix were included in the multivariate models (correlation results not shown). The multivariate approach used to predict health services utilization varied based on the level of measurement for the three dependent variables (alternative health services, hospitalization, and number of ambulatory visits). Multivariate logistic regression was used in the models to identify the predictors of alternative health services use and overnight hospitalizations, as these are binary outcome measures. Negative binomial regression was used to predict the number of ambulatory visits in the 18 months after release, as this was a count outcome measure. For all three dependent variables, a step-wise block approach was used, resulting in four multivariate models for each dependent variable, or a total of 12 multivariate models. Model 1 incorporated only the variables in the Predisposing domain (including both traditional and vulnerable measures). Model 2 included only the variables in the Enabling domain, whereas Model 3 included only the variables in the Need domain. Model 4 was the 
fully specified model as it contained all three theoretical domains. All variance inflation factors were less than 2.0, indicating no concerns with multicollinearity. Results of the multivariate regression models report the adjusted odds ratios or the incidence rate ratios, 95\% confidence intervals, $-2 \log$ likelihood, Model $\chi^{2}$, and Nagelkerke $R^{2}$. Data analyses were conducted using Stata/SE version 12.0.

\section{Results}

\section{Descriptive and bivariate statistics}

Table 1 displays the descriptive statistics for the African American women in the study on the dependent health services utilization variables and the independent variables in the theoretical model. In the 18 months after being released from prison, $39.35 \%$ of the African American women had received health care from an alternative health care source, such as a spiritual or religious counselor or a family member. One in five participants $(21.60 \%)$ had been hospitalized during this same time-frame. The number of ambulatory office visits ranged from zero to 41 , with an average of about seven visits, and a median of 5.00.

The average participant was 36 years old, unmarried (84.53\%), and had one child (mean=1.54, S.D. $=1.78$, range: 0 to 8 ). About half of the participants had a high school degree $(56.35 \%)$ and were employed prior to incarceration (46.96\%). Over one-fourth of the women self-identified as bisexual or lesbian $(26.52 \%)$. Participant's self-rated religiosity was above the midpoint (mean=2.10, S.D. $=.80$, range: .00 to 3.00 ) and $52 \%$ reported being an active member in an organization or social group comprised mostly of members of their own ethnic group. Other variables in the Predisposing vulnerable domain indicated this was an at-risk sample as $18 \%$ had been homeless in the year prior to incarceration and had been incarcerated an average of four times as an adult. Victimization was high with over half of the African American women reporting being physically, sexually or emotionally abused as a child (55.25\%), physically assaulted as an adult (57.00\%), and forced to engage in sex as an adult $(50.00 \%)$. Discrimination based on race and gender was also experienced by African American women in the study (mean=13.94, S.D.=10.71; range .00 to 53.50).

In the Enabling domain, the average annual household income prior to incarceration was around $\$ 18,090$. While two-thirds of the women had health insurance $(66.85 \%)$ and $52.49 \%$ had a usual doctor, the average participant still reported experiencing at least one barrier to health services in the year prior to incarceration (mean=1.61, S.D. $=2.28$; range: .00 to 15.00). Participants scored above the midpoint on the social support scale (mean $=5.23$, S.D. $=1.29$, range: 1.00 to 7.00 ) and the active coping scale (mean=50.68, S.D. $=6.56$, range: 14.00 to 68.00$)$. Almost half (48\%) received some form of public assistance and $19 \%$ received disability benefits.

A variety of measures in the Need domain were examined. Health problems limited daily activities for about one-third (30.00\%) of the incarcerated African American women. Participants reported experiencing an average of two physical health problems and two behavioral health problems across the lifespan. Only $8 \%$ had injected drugs in their lifetime. The lifetime prevalence of STI's (61.88\%) was high, as was the percentage of African American women who screened reactive for HIV or HCV antibodies (17.68\%). More 
specifically, in this sample the prevalence for HIV was 5.0\% (n=9) and the prevalence for HCV was $13.8 \%$ ( $n=25)$, with two participants being co-infected with HIV and HCV.

In order to highlight the health problems faced by African American women in prison and substantiate their need for health services, Table 2 presents the lifetime prevalence of both physical and behavioral health problems. The most commonly reported physical health problems included high blood pressure (36.00\%) and respiratory issues (35.00\%). Interestingly, obesity was only cited by $20.00 \%$ of women as a physical health problem, but height and weight data collected as part of the B-WISE protocol indicated that $52.49 \%$ of the participants are classified as obese with a Body Mass Index (BMI) of 30.00 or higher. About $11 \%$ of participants reported having cancer. Behavioral health problems were common among the African American women with over three-fourths of participants reporting a drug problem $(76.00 \%)$. Likewise, $43.00 \%$ of incarcerated women reported alcohol problems, $54.00 \%$ mental health problems, and 30.00\% PTSD.

Despite the clear need for health services as evidenced by the health problems in Table 2, African American women reported experiencing significant barriers to health care while in prison and in the community prior to incarceration (see Table 3). Overall, health care barriers were significantly more common in the community, with $62.43 \%$ of African American women experiencing at least one barrier to health services in the community as compared with $39.78 \%$ experiencing at least one barrier to health care while incarcerated $(\mathrm{p}=.00)$. The most commonly cited reasons for not using health services in the community were patient-driven. These reasons included African American women's lack of desire for treatment $(24.86 \%)$ or delaying treatment $(24.31 \%)$, both of which were significantly higher in the community than in the prison at $\mathrm{p}=.00(12.15 \%, 2.76 \%$, respectively). Financial barriers were also more salient in the community health care system, as compared with the correctional health care system ( $17.68 \%$ versus $3.31 \%, \mathrm{p}=.00)$. The most frequently mentioned barriers to prison health care included African American women's fears or experiences of discrimination as well as the health care system itself (e.g., could not get an appointment); however, the differences between these barriers in prison versus the community were not statistically significant. The use of drugs or being on the run from law enforcement was a barrier to community health services for $14.36 \%$ of the participants. While incarcerated, only a small percentage $(4.97 \%)$ of women reported barriers that would indicate a lack of trust in health care providers or dissatisfaction with health care provided in prison.

\section{Multivariate models}

Tables 4, 5, and 6 present a series of multivariate models in which each domain of the Behavioral Model for Vulnerable Populations was examined separately as well as a full model which includes the Predisposing, Enabling, and Need domain variables simultaneously. Only variables significantly correlated with any of the three dependent variables in the bivariate analyses (results not shown) were included in the multivariate models. It is noteworthy that variables in the Predisposing traditional domain are not included in any of the multivariate models because they did not reach a statistically significant level in the bivariate analyses. 
The models in Table 4 used multivariate logistic regression to predict African American women's use of alternative health services in the 18 months after release from prison. As displayed in Model 4.1, two of the three Predisposing vulnerable domain variables predicted the use of alternative health services. Religiosity increased the odds of receiving health care from either a spiritual or religious counselor or a family member (A.O.R. $=1.70,95 \%$ C.I: 1.07-2.70). Being an active member of an ethnic community more than doubled the likelihood of African American women's use of alternative sources of health care after community re-entry (A.O.R. $=2.25,95 \%$ C.I: $1.13-4.48$ ). Neither of the variables in the Enabling traditional domain or the Enabling vulnerable domain were significant (see Model 4.2), but one of the Need vulnerable domain variables reached statistical significance in Model 4.3. Specifically, the odds of using alternative sources of health care increased more than two-fold for African American women who screened reactive for either HIV and/or HCV (A.O.R.=2.73, 95\% C.I: 1.04-7.13).

Model 4.4 displays the adjusted odds ratios for the Predisposing, Enabling, and Need domain variables in the full model. More religious African American women (A.O.R.=1.76, 95\% C.I: $1.08-2.88$ ) and those who were actively involved in their ethnic community (A.O.R. $=2.34,95 \%$ C.I: $1.12-4.90$ ) were significantly more likely to use alternative health services, net of the effects of the other variables in the model. In addition, African American women who screened reactive for HIV or HCV while incarcerated were over three times more likely to obtain health care from alternative sources after community re-entry (A.O.R. $=3.22$, 95\% C.I: $1.16-8.94$ ). The full model was statistically significant and provided the best model fit.

The next series of models (see Table 5) also used multivariate logistic regression to predict if an African American woman had been hospitalized overnight in the 18 months after community re-entry. While no variables in Model 5.1 examining the Predisposing vulnerable domain reached a statically significant level, both the Enabling traditional domain and the Enabling vulnerable domain variables in Model 5.2 predicted hospitalizations after being released from prison. Specifically, for each additional community health care barrier, women were $31 \%$ less likely to be hospitalized overnight. Moreover, African American women who received social security disability insurance were 3.67 times more likely to be hospitalized overnight. Variables in the Need traditional and the Need vulnerable domains (Model 5.3) did not predict hospitalizations. Overall, Model 5.4 provided the best fit for the data and both traditional and vulnerable Enabling domain variables remained significant and in the same direction in the full model. The greater the number of barriers to community health care reported by African American women, the lower the likelihood of being hospitalized overnight (A.O.R. $=.64$, 95\% C.I: .46-.89). Also, women who received disability were estimated to be over 3.20 times more likely than those without disability benefits to be hospitalized.

Negative binomial regression was used in Table 6 to predict the number of ambulatory office visits made by African American women in the 18 months after being released from prison. As displayed in the Model 6.1 containing the variables in the Predisposing vulnerable domain, experiences of gendered racism were positive predictors of greater ambulatory service utilization (I.R.R.=1.02, 95\% C.I: 1.01-1.04). Neither the Enabling traditional 
domain nor the Enabling vulnerable domain variables in Model 6.2 were significant; however, one Need traditional domain variable in Model 6.3 predicted more frequent use of ambulatory health care. More physical health problems increased the use of outpatient services (I.R.R. $=1.15,95 \%$ C.I: $1.05-1.25$ ).

Model 6.4 displays the fully specified model predicting the number of ambulatory office visits. In the Predisposing vulnerable domain, experiencing gendered racism still increased the number of times ambulatory services were used (I.R.R.=1.02, 95\% C.I: $1.00-1.03$ ). The traditional variable in the Need domain, number of physical health problems, remained a significant predictor of ambulatory service use (I.R.R.=1.12, 95\% C.I: $1.02-1.23$ ), net of the effects of the other variables in the full model. Additionally, the Need vulnerable domain variable of HIV and/or HCV positive status reached statistical significance in the full model indicating that those participants who screened reactive for either HIV and/or HCV (I.R.R. $=1.54,95 \%$ C.I: $1.00-2.36$ ) used significantly more ambulatory services after community re-entry. Overall, Model 6.4 was statistically significantly and provided the best model fit for predicting the number of ambulatory outpatient visits.

\section{Discussion}

Women re-entering society after a period of incarceration are in a particularly precarious position in terms of their health status, with a number of factors predisposing them to poorer health outcomes. African American women are especially vulnerable, given higher rates of incarceration among this population, as well as limited resources and exposure to factors that may adversely shape their health. Specifically, African American women re-entering their communities encounter significant barriers to maintaining their health and well-being, exacerbated by their multiple marginalized status (i.e., race, class, and gender). The purpose of this research was to describe the overall health of African American women recently released from prison, as well as the barriers to utilizing health services both during incarceration and in the community. Further, predictors of three types of health service utilization were investigated using the Behavioral Model for Vulnerable Populations, ${ }^{4}$ yielding important insights for this at-risk population.

As anticipated, results of this research reveal that African American women experience a wide range of physical and behavioral health problems, including elevated blood pressure and respiratory problems, as well as high rates of substance abuse and mental health problems. Additionally, high lifetime rates of STI's and reactive HIV or HCV screening tests completed during the study timeframe further indicate that these women have important health problems that require regular monitoring or other intervention by health care providers. These findings align with past research that indicates incarcerated women are more likely than those in the general population to experience a variety of health problems, including substance abuse and related illnesses like hepatitis, cirrhosis, and HIV/ AIDS. ${ }^{13,14,53}$

Despite health needs, findings indicate that African American women also report important barriers to health care both while incarcerated and in the community. Though some prior research suggests incarcerated women face substandard health care during their 
imprisonment - especially among pregnant and older women ${ }^{54-56}$ - findings of this study align with previous studies that highlight the significant health care challenges continue when women re-enter the community. Specifically, though a greater percentage of women identify unfair treatment or discrimination and the health care system as barriers to accessing services while incarcerated, all other barriers examined are more likely to be cited by women while in the community. For women re-entering the community after a period of incarceration, competing demands of greater urgency, such as securing housing and employment, reestablishing social relationships with family members and friends, and reunification with children may delay or otherwise complicate the transition from prisonbased health care to community-based services. ${ }^{53}$

Further, problems regarding the continuity of medical care upon re-entry can inhibit women's use of needed health services. Research indicates that continuity of care and adherence to prescribed medical treatment suffer greatly among recently released populations, with sharp declines in use of prescribed medications and other treatment for mental health disorders. ${ }^{57}$ This is the especially relevant for those who have co-occurring mental health and substance use disorders, for which the stress of re-entry may precipitate relapse and/or aggravate mental health problems. ${ }^{56}$ Among those with infectious diseases, continuity of and compliance with prescribed treatment(s) are essential for maintaining individual and public health. For those who are HIV positive, for example, discontinuing anti-retroviral medications can result in drug resistance and increased viral load, making disease transmission more likely in the event that discordant HIV-status individuals engage in risk behaviors like unprotected sex. ${ }^{58}$ With estimates suggesting nearly three-quarters of all criminal justice involved women with substance use disorders have co-occurring mental disorders, this revolving door of criminal behavior, relapse, illness, and incarceration is a significant problem for this population. ${ }^{14}$ For the African American women in this study, the cost of medical care outside of prison, coupled with high rates of substance abuse problems, contribute to a post-incarceration context unfavorable to accessing health care services in their communities. Though prison based health care services are not without welldocumented problems, ${ }^{15-17}$ this research suggests that African American women may experience fewer barriers and be more willing to seek care while incarcerated.

The key goal of this research was to use the Behavioral Model for Vulnerable Populations ${ }^{4}$ to examine predictors of different types of health service utilization, including the use of alternative sources of care, overnight hospitalization, and ambulatory visits in the 18 months following release. This research extends the model to a previously unexamined population, re-entering African American women, who experience multiple disadvantaged statuses that shape their health and health service utilization. As already described, findings of this study show that compared with the general population, women re-entering the community have a greater number of vulnerabilities that may adversely shape their health. Importantly, in the full multivariate models presented, vulnerable domain variables are the most robust predictors for all three types of health service utilization examined, supporting the first hypothesis. Overall, these findings provide strong support for the Behavioral Model for Vulnerable Populations. 
The results of this research also provide a more nuanced picture of how factors in the Predisposing domain differ depending on the type of health care sought. That is, the significant association for the vulnerable domains did vary based on the type of service examined. As predicted in the second hypothesis, culturally-specific variables in the vulnerable domains predict an increase in the use of alternative services. Specifically, religiosity and ethnic community membership predict greater odds of using alternative health services in the 18 months after release. However, contrary to what was expected, these measures did not significantly impede use of traditional health care services. Use of traditional health services, in partial support of the hypothesis, are significantly predicted by poorer health such that women who are vulnerable, either due to disability or HIV/HCV infection, appear more likely to have overnight hospitalizations and use ambulatory services, respectively.

These findings demonstrate that while more religious African American women have greater odds of using alternative health care services - as past research has suggested - they are not necessarily less likely to use the traditional health services examined. ${ }^{29}$ These results may be partially explained by the type of traditional services examined. Specifically, both outpatient visits and overnight hospitalizations may be the result of chronic health problems (and their presenting acute symptoms), for which traditional medical care may be perceived as the best or only remedial option. These results, for example, cannot be extended for other forms of health care like mental health or substance abuse treatment, for which utilization may be more significantly shaped by subjective perceptions of illness and symptoms, and for whose treatment may be considered outside the scope of traditional medicine. ${ }^{59}$

In partial support of the third hypothesis, findings demonstrate that the Predisposing domain also plays an important role in explaining the use of both alternative and ambulatory outpatient visits. Though Enabling domain factors did not predict use of alternative or ambulatory services, this research reveals that cultural factors significantly shape traditional and non-traditional health service utilization for African American women. That gendered racism positively predicts use of outpatient health services, even after controlling for other factors, is particularly concerning. To date, a number of studies have documented the relationship between discriminatory experiences and negative health outcomes in minority populations. ${ }^{60-62}$ African American women's experiences of gendered racism, particularly, have been linked to increased stress and risk of poor health and wellbeing, including suicidal ideation and more significant depressive symptoms. ${ }^{57,63}$

Among the women in this study, it may be the case that experiences of gendered racism serve as stressors that trigger negative health behaviors like substance use or overeating, as has been found in past research. ${ }^{64}$ Alternatively, chronic stress associated with discriminatory experiences may also serve to weaken immune function, which can make individuals more susceptible to illness and disease. ${ }^{65}$ In this way, experiencing discrimination can contribute to poorer overall health, prompting utilization of outpatient services. In any case, the results of this study suggest that African American female offenders may be especially vulnerable to the adverse effects of gendered racism, which are likely compounded by their other marginalized statuses (i.e., socioeconomic status and criminal history) and limited resources during the re-entry period. 
Finally, results of this study provide some support for the fourth hypothesis, which proposed that Enabling and Need factors would be significant predictors of overnight hospitalization during the 18-months after release. As the number of self-reported barriers to health care increase, the odds of overnight hospitalization significantly decrease. This finding aligns with expectations, and suggests that for costly and invasive services like overnight hospital stays, factors in the Enabling domain play a more significant role in utilization decisions. Although HIV/HCV serostatus positively predicted the other types of health care examined, it did not significantly predict overnight hospitalization. This is surprising given that women with HIV or HCV tend to have poorer overall health and greater need for ongoing treatment associated with these chronic and life-threatening conditions. ${ }^{22,57}$ It may be that the viruses were diagnosed early and/or that symptoms are well managed through outpatient and alternative health care options thereby not necessitating overnight hospital stays.

\section{Limitations}

This research has a few noteworthy limitations. First, data collected as part of the B-WISE prison sample do not necessarily reflect the characteristics of African American female prisoners nationally as they were collected from prisons in one southern state. Further, the relatively small sample size limits generalizability to a broader population. Additionally, because the current research is based on retrospective self-reported health problems at Wave 1 , there is the possibility of recall error and self-report bias. However, it is likely that this type of bias has resulted in an underreporting of health problems and health services utilization; thus, further emphasizing the importance of the study. In particular, the results of this research highlight a number of significant Predisposing, Enabling, and Need domain factors that are likely salient among African American women re-entering the community after a period of incarceration. Future research addressing health behaviors and service utilization among this population would benefit from considering the role of the vulnerability measures included in this study. Finally, while a unique contribution of this research was the examination of three types of health care, future research would benefit from examining more specific types of service utilization (e.g., substance abuse treatment and use of mental health services) and considering the context surrounding the use of services (e.g., specific health problem[s] addressed).

\section{Conclusions}

In all, the findings of this study respond to the call for additional research on the adverse effects of incarceration on the health of African American women by shedding light on the health and health behaviors of African American women re-entering their communities after release from prison. ${ }^{40-42}$ As this research demonstrates, marginalized and vulnerable populations have a number of health needs that may go unattended as these groups face considerable re-entry challenges with limited resources. Findings of this study indicate that clinicians and policy makers must consider and understand the important role that the vulnerable domain plays in certain health issues as well as offenders' access to and use of health services. For example, vulnerable domain variables such as sexual victimization or behavioral health problems could contribute to poor sexual health outcomes. In revealing the importance of cultural factors like gendered racism and religiosity in patterning certain types of health service utilization, this research expands what is known about how African 
American women's unique social location influences their behaviors after their release from prison.

The findings of this study provide a number of important implications for improving the health and health service utilization of re-entering African American women. Implications of this research indicate that these women, especially those with serious health concerns like $\mathrm{HIV}$ and/or HCV, would benefit from greater attention to coordinating health care as they transition from prison to the community. Working to establish a plan for community-based care while still incarcerated may increase the likelihood these individuals will utilize health services upon release. Furthermore, given evidence that the health care needs of incarcerated populations may go unaddressed while in prison or jail, increased efforts should be made to enhance the quality and quantity of services offered to offenders. ${ }^{15}$ Providing healthpromoting knowledge, screening, and treatment options to incarcerated populations benefits not only the individuals treated, but also those in the communities that they return to after release. In addition to stemming the potential spread of disease, such efforts also reduce the financial and other burdens these communities would otherwise incur in providing more costly services to recently released populations whose unaddressed health care needs may have compounded. Importantly, with the Affordable Care Act, health care is more widely accessible in the United States than ever before. However, additional research is needed to examine how the needs of vulnerable populations, like those recently released from correctional facilities, are being met and unmet under this new system. Though continuity of care in this difficult transition period is still imperfect, greater prison-based coordination of care and aftercare may begin to address some of the health disparities experienced by this vulnerable population of African American women. Maintaining good health by reducing the stress and uncertainty of re-entry are key for marginalized populations as they focus on establishing stable, crime-free futures.

\section{Acknowledgments}

This research is funded by the National Institute on Drug Abuse (R01-DA022967, PI: Oser; K02-DA035116, PI: Oser; and K08-DA032296, PI: Stevens-Watkins). This research would not have been possible without the Department of Corrections participation; however, the findings and ideas presented are solely those of the authors. We appreciate the women who shared their stories and want to acknowledge the contribution of the interviewers and community partners.

\section{References}

1. Glaze, LE.; Kaeble, D. Correctional populations in the United States, 2013. Washington, DC: US Department of Justice, Office of Justice Programs, Bureau of Justice Statistics; 2014 Dec. p. 13Report No.: NCJ 248479

2. Carson, EA.; Golinelli, D. Prisoners in 2012: Trends in admissions and releases, 1991-2012. Washington, DC: US Department of Justice, Office of Justice Programs, Bureau of Justice Statistics; 2013 Dec. p. 44Report No.: NCJ 243920

3. Aday L. Health status of vulnerable populations. Annu Rev Public Health. 1994 May.15:487-509. [PubMed: 8054096]

4. Gelberg L, Andersen RM, Leake BD. The Behavioral Model for Vulnerable Populations: Application to medical care use and outcomes for homeless people. Health Ser Res. 2000 Feb; 34(6):1273-1302. 
5. Ward EC, Clark L, Heidrich S. African American women's beliefs, coping behaviors, and barriers to seeking mental health services. Qual Health Res. 2009 Nov; 19(11):1589-1601. [PubMed: 19843967]

6. Brubaker MD, Amatea EA, Torres-Rivera E, et al. Barriers and supports to substance abuse service use among homeless adults. J Addict Offender Couns. 2013 Oct; 34(2):81-98.

7. Gelberg L, Roberston MJ, Arangua L, et al. Prevalence, distribution, and correlates of hepatitis C virus infection among homeless adults in Los Angeles. Public Health Rep. 2012 Jul-Aug;127(4): 407-421. [PubMed: 22753984]

8. Kilbourne AM, Herndon B, Andersen RM, et al. Psychiatric symptoms, health services, and HIV risk factors among homeless women. J Health Care Poor Underserved. 2002 Feb; 13(1):49-65. [PubMed: 11836913]

9. Rhoades H, Wenzel SL, Golinelli D, et al. Predisposing, enabling and need correlates of mental health treatment utilization among homeless men. Community Ment Health J. 2014 Nov; 50(8): 943-952. [PubMed: 24595594]

10. Teruya C, Longshore D, Andersen RM, et al. Health and health care disparities among homeless women. Women Health. 2010 Dec; 50(8):719-736. [PubMed: 21170815]

11. Leukefeld CG, Logan TK, Martin SS, et al. A health services use framework for drug-abusing offenders. Am Behan Sci. 1998 May; 41(8):1123-1135.

12. Webster JM, Mateyoke-Scrivener A, Rosen PJ, et al. Behavioral health services use among drugabusing offenders: Additional support for a modified Andersen and Newman framework. Corrections Compendium. 2006 Jul-Aug;31(4):1-6.

13. Maruschak, LM.; Berzofsky, M.; Unangst, J. Medical problems of state and federal prisoners and jail inmates, 2011-12. Washington, DC: US Department of Justice, Office of Justice Programs, Bureau of Justice Statistics; 2015 Feb. p. 23Report No.: NCJ 248491

14. James, DJ.; Glaze, LE. Mental health problems of prison and jail inmates. Washington, DC: US Department of Justice, Office of Justice Programs, Bureau of Justice Statistics; 2006 Sep. p. 12Report No.: NCJ 213600

15. National Commission on Correctional Health Care. The health status of soon-to-be-released inmates: A report to congress. Vol. 1. Washington, DC: National Institute of Justice, Office of Justice Programs, U.S. Department of Justice; 2002.

16. Colbert AM, Sekula LK, Zoucha R, et al. Health care needs of women immediately postincarceration: A mixed methods study. Public Health Nurs. 2013 Sep-Oct;30(5):409-419. [PubMed: 24000913]

17. Kulkarni SP, Baldwin S, Lightstone AS, et al. Is incarceration a contributor to health disparities? Access to care of formerly incarcerated adults. J Community Health. 2010 Jun; 35(3):268-274. [PubMed: 20127504]

18. Ahalt C, Trestman RL, Rich JD, et al. Paying the price: the pressing need for quality, cost, and outcomes data to improve correctional health care for older prisoners. J Am Geriatr Soc. 2013 Nov; 61(11):2013-2019. [PubMed: 24219203]

19. Andersen R, Nemwan JF. Societal and individual determinants of medical care utilization in the United States. Millbank Mem Fund Q Health Soc. 1973; 51(1):95-124.

20. Castañeda SF, Malcarne VL, Foster-Fishman PG, et al. Health care access and breast cancer screening among Latinas along the California-Mexican border. J Immigr Minor Health. 2014 Aug; 16(4):670-681. [PubMed: 24150421]

21. Oser CB, Leukefeld CG, Tindall MS, et al. Rural drug users: Factors associated with substance abuse treatment utilization. Int J Offender Ther Comp Criminal. 2011 Jun; 55(4):567-586.

22. Varga LM, Surratt HL. Predicting health care utilization in marginalized populations: Black, female, street-based sex workers. Womens Health Issues. 2014 May-Jun;24(3):e335-e343. [PubMed: 24657047]

23. Corbie-Smith G, Thomas SB, Williams MV, et al. Attitudes and beliefs of African Americans toward participation in medical research. J Gen Intern Med. 1999 Sep; 14(9):537-546. [PubMed: 10491242]

24. Fullilove MT, Fullilove RE. Stigma as an obstacle to AIDS action: The case of the African American community. Am Behav Sci. 1999 Apr; 42(7):1117-1129. 
25. Chandler D. The underutilization of health services in the Black community: An examination of causes and effects. J Black Stud. 2010 May; 40(5):915-931.

26. Giger JN, Appel SJ, Davidhizar R, et al. Church and spirituality in the lives of the African American community. J Transcult Nurs. 2008 Jul; 19(4):375-383. [PubMed: 18650398]

27. Gilbert, DJ.; Wright, EM., editors. African American women and HIV/AIDS: Critical responses. Westport, CT: Praeger Publishers; 2003.

28. Staton-Tindall M, Duvall J, Stevens-Watkins D, et al. The role of spirituality in the relationship between traumatic life events, mental health, and drug use among African American women from one southern state. Subst Use Misuse. 2013 Sep; 48(12):1246-1257. [PubMed: 24041186]

29. Jones, RL. Black psychology. Oakland, CA: Cobb \& Henry Publishers; 2004.

30. Pullen E, Perry B, Oser C. African American women's preventative care usage: The role of social support and racial experiences and attitudes. Sociol Health Illn. 2014 Apr; 36(7):1037-1053. [PubMed: 24749849]

31. James SA, Hartnett SA, Kalsbeek WD. John Henryism and blood pressure among Black men. J Behav Med. 1983 Sep; 6(3):259-278. [PubMed: 6663614]

32. James SA. John Henryism and the health of African Americans. Cult Med Psychiatry. 1994 Jun; 18(2):163-182. [PubMed: 7924399]

33. Dressler WW, Bindon JR, Negger YH. John Henryism, gender, and arterial blood pressure in an African American community. Psychosom Med. 1998 Sep-Oct;60(5):620-624. [PubMed: 9773768]

34. Light KC, Brownley KA, Turner JR, et al. Job status and high-effort coping influence work blood pressure in women and blacks. Hypertension. 1995 Apr; 25(4):554-559. [PubMed: 7721397]

35. Chatters L, Taylor RJ, Neighbors HW. Size of informal helper network mobilized during a serious personal problem among black Americans. J Marriage Fam. 1989 Aug; 51(3):667-676.

36. Neighbors HW, Jackson J. The use of informal and formal help: Four patterns of illness behavior in the Black community. Am J Community Psychol. 1984 Dec; 12(6):629-644. [PubMed: 6524587]

37. Pullen, E.; Oser, C. Disadvantaged status and health matters networks among low-income African American women. 2016. Paper under review

38. Stack, C. All our kin: Strategies for survival in a black community. New York, NY: Harper and Row; 1974.

39. Johnson KS, Elbert-Avila KI, Tulsky JA. The influence of spiritual beliefs and practices on the treatment preferences of African Americans: A review of the literature. J Am Geriatr Soc. 2005 Apr; 53(4):711-719. [PubMed: 15817022]

40. Braithwaite RL, Treadwell HM, Arriola K. Health disparities and incarcerated women: A population ignored. Am J Public Health. 2005 Oct; 95(10):1679-1681. [PubMed: 16186446]

41. Freudenberg N. Adverse effects of US jail and prison policies on the health and well-being of women of color. Am J Public Health. 2002 Dec; 92(12):1895-1899. [PubMed: 12453803]

42. Iguchi MY, Bell J, Ramchand RN, et al. How criminal system racial disparities may translate into health disparities. J Health Care Poor Underserved. 2005 Nov; 16(4):48-56. [PubMed: 16327107]

43. Dumont DM, Brockmann B, Dickman S, et al. Public health and the epidemic of incarceration. Annu Rev Public Health. 2012 Apr.33:325-339. [PubMed: 22224880]

44. Hammett TM, Harmon MP, Rhodes W. The burden of infectious disease among inmates of and releasees from US correctional facilities, 1997. Am J Public Health. 2002 Nov; 92(11):1789-1794. [PubMed: 12406810]

45. Divine BT, Greby SM, Hunt KV, et al. Revised guidelines for HIV counseling, testing, and referral. MMWR Recomm Rep. 2001 Nov; 50(RR19):1-58.

46. World Health Organization. Rapid HIV tests; Guidelines for use in HIV testing and counselling services in resource-constrained settings. Geneva: World Health Organization, Department of HIV/ AIDS; 2004.

47. Phinney J. The multigroup ethnic identity measure: A new scale for use with adolescents and young adults from diverse groups. J Adolesc Res. 1992 Apr; 7(2):156-176.

48. Dennis, ML.; Titus, JC.; White, MK., et al. Global Appraisal of Individual Needs: Administration guide for the GAIN and related measures. Bloomington, IL: Chestnut Health Systems; 2002. 
49. Bowleg L, Neilands TB, Choi KH. Evaluating the validity and reliability of a modified schedule of sexist events: Implications for public health research on women's HIV risk behaviors. Women Health. 2008; 47(2):19-40. [PubMed: 18681099]

50. Landrine H, Klonoff EA. The schedule of racist events: A measure of racial discrimination and a study of its negative physical and mental health consequences. J Black Psychol. 1996 May; 22(2): 144-168. 1996.

51. Perry B, Pullen E, Oser C. Too Much of a Good Thing? Psychosocial resources, gendered racism, and suicidal ideation among low-socioeconomic status African American women. Soc Psychol Q. 2012 Dec; 75(4):334-359. [PubMed: 23565018]

52. Zimet GD, Dahlem NW, Zimet SG, et al. The multidimensional scale of perceived social support. J Pers Assess. 1988; 42(1):30-41.

53. Binswanger IA, Krueger PM, Steiner JF. Prevalence of chronic medical conditions among jail and prison inmates in the United States compared with the general population. J Epidemiol Community Health. 2009 Nov; 63(11):912-919. [PubMed: 19648129]

54. Aday, RH.; Krabill, JJ. Women aging in prison: A neglected population in the correctional system. Boulder, CO: Lynne Rienner Publishers; 2011.

55. Ferszt GG, Clarke JG. Health care of pregnant women in U.S. state prisons. J Health Care Poor Underserved. 2012 May; 23(2):557-569. [PubMed: 22643607]

56. Johnson, JE.; Schonbrun, YC.; Peabody, ME., et al. J Behav Health Serv Res. 2014 Mar. Provider experiences with prison care and aftercare for women with co-occurring mental health and substance use disorders: treatment, resource, and systems integration challenges. [Epub ahead of print]

57. Mallik-Kane, K.; Visher, CA. Health and prisoner reentry: How physical, mental, and substance abuse conditions shape the process of reintegration. Washington, DC: The Urban Institute, Justice Policy Center; 2008 Feb.

58. Howard AA, Arnsten JH, Lo Y, et al. A prospective study of adherence and viral load in a large multicenter cohort of HIV-infected women. AIDS. 2002 Nov; 16(16):2175-2182. [PubMed: 12409739]

59. Robinson-Brown, D.; Keith, V. In and out of our right minds: The mental health of African American women. New York, NY: Columbia University Press; 2013.

60. Roberts CB, Vines AI, Kaufman JS, et al. Cross-sectional association between perceived discrimination and hypertension in African-American men and women: The Pitt County study. Am J Epidemiol. 2008 Mar; 167(5):624-632. [PubMed: 18083714]

61. Mays VM, Cochran SD, Barnes NW. Race, race-based discrimination, and health outcomes among African Americans. Annu Rev Psychol. 2007 Jan.58:201-25. [PubMed: 16953796]

62. Pascoe EA, Smart Richman L. Perceived discrimination and health: A meta-analytic review. Psychol Bull. 2009 Jul; 135(4):531-554. [PubMed: 19586161]

63. Perry BL, Harp KL, Oser CB. Racial and gender discrimination in the stress process: Implication for African American women's health and well-being. Sociol Perspect. 2013 Mar; 56(1):25-48. [PubMed: 24077024]

64. Gee GC, Delva J, Takeuchi DT. Relationships between self-reported unfair treatment and prescription medication use, illicit drug use, and alcohol dependence among Filipino Americans. Am J Public Health. 2007 Dec; 97(5):933-940. [PubMed: 16809581]

65. Segerstrom SC, Miller GE. Psychological stress and the human immune system: A meta-analytic study of 30 years of inquiry. Psychol Bull. 2004 Jul; 130(4):601-630. [PubMed: 15250815] 


Predisposing $\longrightarrow$ Enabling $\longrightarrow$ Need $\longrightarrow$ Health Behavior

\section{Traditional Domain}

Age

Marital status

Education

Children

Employment status

$\underline{\text { Vulnerable Domain }}$

Sexual orientation

Homelessness

Incarceration history

Religiosity

Victimization

Race-based stress

Ethnic community member
Traditional Domain

Perceived physical health issues

Health limits physical activity

Regular source of care

Social support

Barriers to care

$\frac{\text { Vulnerable Domain }}{\text { Public benefits }}$
Disability
Coping skills

Service Utilization

Ambulatory care Hospitalization

Alternative health services

Figure 1.

Applied Behavioral Model for Vulnerable Populations for African American Women During Re-Entry 
Table 1

Descriptive Statistics of African American Women in Prison ( $\mathrm{n}=181)$

\begin{tabular}{|c|c|c|c|c|}
\hline & Percent & Mean & S.D. & Range \\
\hline \multicolumn{5}{|c|}{ Health Services Utilization in the 18 Months after Re-entry (Dependent Variables) } \\
\hline Alternative Health Services & $39.35 \%$ & & & \\
\hline Hospitalization Overnight & $21.60 \%$ & & & \\
\hline \# of Ambulatory Visits & & 7.30 & 7.75 & $.00-41.00$ \\
\hline \multicolumn{5}{|l|}{ Predisposing Traditional } \\
\hline Age & & 36.80 & 9.47 & $20.00-62.00$ \\
\hline Married & $15.47 \%$ & & & \\
\hline High School Degree & $56.35 \%$ & & & \\
\hline Number of Kids & & 1.54 & 1.78 & $.00-8.00$ \\
\hline Employed Prior to Incarceration & $46.96 \%$ & & & \\
\hline \multicolumn{5}{|l|}{ Predisposing Vulnerable } \\
\hline Sexual Minority & $26.52 \%$ & & & \\
\hline Homeless in Year Prior to Incarceration & $18.00 \%$ & & & \\
\hline \# of Times Incarcerated & & 4.11 & 4.29 & $1.00-25.00$ \\
\hline Religiosity & & 2.10 & .80 & $.00-3.00$ \\
\hline Active Member of Ethnic Community & $52.00 \%$ & & & \\
\hline Childhood Victimization & $55.25 \%$ & & & \\
\hline Adult Physical Victimization & $57.00 \%$ & & & \\
\hline Adult Sexual Victimization & $50.00 \%$ & & & \\
\hline Gendered Racism Scale & & 13.94 & 10.71 & $.00-53.50$ \\
\hline \multicolumn{5}{|l|}{ Enabling Traditional } \\
\hline Household Income Prior to Incarceration & & 18.09 & 18.47 & $2.50-87.50$ \\
\hline Health Insurance Prior to Incarceration & $66.85 \%$ & & & \\
\hline Usual Doctor & $52.49 \%$ & & & \\
\hline \# Barriers to Community Healthcare & & 1.61 & 2.28 & $.00-15.00$ \\
\hline Social Support Scale & & 5.23 & 1.29 & $1.00-7.00$ \\
\hline \multicolumn{5}{|l|}{ Enabling Vulnerable } \\
\hline Active Coping Scale & & 50.68 & 6.56 & $14.00-68.00$ \\
\hline Public Benefits & $48.00 \%$ & & & \\
\hline Disability & $19.00 \%$ & & & \\
\hline \multicolumn{5}{|l|}{ Need Traditional } \\
\hline Health Limits Activities & $30.00 \%$ & & & \\
\hline \# Physical Health Problems & & 2.23 & 1.99 & $.00-10.00$ \\
\hline \multicolumn{5}{|l|}{ Need Vulnerable } \\
\hline Injection Drug User & $8.00 \%$ & & & \\
\hline \# of Behavioral Health Problems & & 2.03 & 1.20 & $.00-4.00$ \\
\hline Sexually Transmitted Infection & $61.88 \%$ & & & \\
\hline $\mathrm{HIV} / \mathrm{HCV}$ & $17.68 \%$ & & & \\
\hline
\end{tabular}




\section{Table 2}

Prevalence of Physical Health Problems and Behavioral Health Problems among African American Women in Prison $(\mathrm{n}=181)$

\begin{tabular}{|c|c|c|}
\hline & Percentage & $\mathbf{N}$ \\
\hline Physical Health Problems, Lifetime & & \\
\hline Respiratory & $35.00 \%$ & 64 \\
\hline Muscle/Bone & $23.00 \%$ & 42 \\
\hline Liver & $9.00 \%$ & 17 \\
\hline High Blood Pressure & $36.00 \%$ & 65 \\
\hline High Cholesterol & $12.00 \%$ & 21 \\
\hline Heart Attack or Stroke & $8.00 \%$ & 14 \\
\hline Obesity & $20.00 \%$ & 37 \\
\hline Stomach/Digestive & $17.00 \%$ & 30 \\
\hline Nervous System & $14.00 \%$ & 26 \\
\hline Skin & $14.00 \%$ & 26 \\
\hline Eye, Ear, Nose, or Throat & $23.00 \%$ & 42 \\
\hline Cancer & $11.00 \%$ & 20 \\
\hline Behavioral Health Problems, Lifetime & & \\
\hline Alcohol & $43.00 \%$ & 77 \\
\hline Drug & $76.00 \%$ & 137 \\
\hline Mental Health & $54.00 \%$ & 98 \\
\hline PTSD & $30.00 \%$ & 55 \\
\hline
\end{tabular}

롤

ᄅ

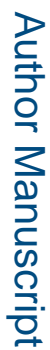

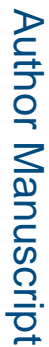

J Health Care Poor Underserved. Author manuscript; available in PMC 2017 January 01. 
Table 3

African American Women's Barriers to Health Care in the Community Prior to Incarceration versus in Prison $(\mathrm{n}=181)$

\begin{tabular}{|l|c|c|c|}
\hline & $\begin{array}{c}\text { Community Health Care } \\
\text { Barriers }\end{array}$ & $\begin{array}{c}\text { Prison Health Care } \\
\text { Barriers }\end{array}$ & $\begin{array}{c}\text { McNemar Test Statistic (2- } \\
\text { sided) }\end{array}$ \\
\hline Experienced Any Barriers & $62.43 \%$ & $39.78 \%$ & $\mathrm{p}=.00$ \\
Barrier Categories: & $24.86 \%$ & $12.15 \%$ & $\mathrm{p}=.00$ \\
Did Not Want Treatment & $24.31 \%$ & $2.76 \%$ & $\mathrm{p}=.00$ \\
Procrastination & $17.68 \%$ & $3.31 \%$ & $\mathrm{p}=.00$ \\
Cost & $12.15 \%$ & $14.92 \%$ & $\mathrm{p}=.42$ \\
Unfair Treatment/Discrimination & $11.05 \%$ & $14.36 \%$ & $\mathrm{p}=.84$ \\
Health Care System & $10.50 \%$ & $9.39 \%$ & - \\
Fear of Diagnosis or Clinical Treatment & & & - \\
Community-Specific Barriers: & $14.36 \%$ & - & - \\
Using Drugs or Absconding & $9.94 \%$ & - & - \\
Logistical Life Barriers & & $4.97 \%$ & - \\
Prison-Specific Barrier: & - & & - \\
Dissatisfaction with Prison Health Care & & & - \\
\hline
\end{tabular}

Note: Participants could site multiple barriers 
Table 4

Multivariate Logistic Regression Results Predicting African American Women's Use of Alternative Health Services in the 18 Months After Released from Prison $(\mathrm{N}=155)$

\begin{tabular}{|c|c|c|c|c|}
\hline & $\frac{\text { Model 4.1 }}{\text { A.O.R. }}$ & $\begin{array}{c}\frac{\text { Model 4.2 }}{\text { A.O.R. }} \\
\text { (95\% C.I.) }\end{array}$ & $\frac{\text { Model 4.3 }}{\text { A.O.R. }}$ & $\frac{\text { Model 4.4 }}{\text { A.O.R. }}$ \\
\hline \multicolumn{5}{|l|}{ Predisposing Vulnerable } \\
\hline Religiosity & $\begin{array}{c}1.70 * \\
(1.07-2.70)\end{array}$ & & & $\begin{array}{c}1.76^{*} \\
(1.08-2.88)\end{array}$ \\
\hline Ethnic Community & $\begin{array}{c}2.25^{*} \\
(1.13-4.48)\end{array}$ & & & $\begin{array}{c}2.34^{*} \\
(1.12-4.90)\end{array}$ \\
\hline Gendered Racism Scale & $\begin{array}{c}.99 \\
(.95-1.02)\end{array}$ & & & $\begin{array}{c}.99 \\
(.95-1.03)\end{array}$ \\
\hline \multicolumn{5}{|l|}{ Enabling Traditional } \\
\hline \# Barriers to Community Health Care & & $\begin{array}{c}1.02 \\
(.88-1.18\end{array}$ & & $\begin{array}{c}.97 \\
(.82-1.14)\end{array}$ \\
\hline \multicolumn{5}{|l|}{ Enabling Vulnerable } \\
\hline Disability & & $\begin{array}{c}.52 \\
(.21-1.27)\end{array}$ & & $\begin{array}{c}.41 \\
(.14-1.23)\end{array}$ \\
\hline \multicolumn{5}{|l|}{ Need Traditional } \\
\hline Health Limits Activity & & & $\begin{array}{c}.61 \\
(.27-1.36)\end{array}$ & $\begin{array}{c}.51 \\
(.22-1.22)\end{array}$ \\
\hline \# Physical Health Problems & & & $\begin{array}{c}1.17 \\
(.97-1.42)\end{array}$ & $\begin{array}{c}1.23 \\
(.98-1.55)\end{array}$ \\
\hline \multicolumn{5}{|l|}{ Need Vulnerable } \\
\hline Injection Drug User & & & $\begin{array}{c}.83 \\
(.22-3.20)\end{array}$ & $\begin{array}{c}1.14 \\
(.27-4.80)\end{array}$ \\
\hline $\mathrm{HIV} / \mathrm{HCV}$ & & & $\begin{array}{c}2.73^{*} \\
(1.04-7.13)\end{array}$ & $\begin{array}{c}3.22 * \\
(1.16-8.94)\end{array}$ \\
\hline-2 log likelihood & 193.60 & 205.59 & 199.16 & 180.92 \\
\hline Model $\chi^{2}$ & $14.20^{* *}$ & 2.20 & $8.64^{*}$ & $26.88^{* * * *}$ \\
\hline Nagelkerke $\mathrm{R}^{2}$ & .12 & .02 & .07 & .22 \\
\hline
\end{tabular}

Notes:

* $<<.05$;

** $\mathrm{p}<.01$;

*** $\mathrm{p}<.001$;

A.O.R. $=$ Adjusted Odds Ratio, 95\% C.I. $=95 \%$ Confidence Interval 
Table 5

Multivariate Logistic Regression Results Predicting African American Women's Overnight Hospitalization in the 18 Months After Released from Prison $(\mathrm{N}=162)$

\begin{tabular}{|c|c|c|c|c|}
\hline & $\begin{array}{l}\frac{\text { Model 5.1 }}{\text { A.O.R. }} \\
\text { (95\% C.I.) }\end{array}$ & $\begin{array}{l}\frac{\text { Model 5.2 }}{\text { A.O.R. }} \\
\text { (95\% C.I.) }\end{array}$ & $\begin{array}{l}\frac{\text { Model 5.3 }}{\text { A.O.R. }} \\
\text { (95\% C.I.) }\end{array}$ & $\begin{array}{l}\text { Model 5.4 } \\
\text { A.O.R. } \\
\text { (95\% C.I.) }\end{array}$ \\
\hline \multicolumn{5}{|l|}{ Predisposing Vulnerable } \\
\hline Religiosity & $\begin{array}{c}.79 \\
(.50-1.25)\end{array}$ & & & $\begin{array}{c}.67 \\
(.41-1.12)\end{array}$ \\
\hline Ethnic Community & $\begin{array}{c}.93 \\
(.43-2.03)\end{array}$ & & & $\begin{array}{c}1.00 \\
(.41-2.47)\end{array}$ \\
\hline Gendered Racism Scale & $\begin{array}{c}1.02 \\
(.99-1.06)\end{array}$ & & & $\begin{array}{c}1.00 \\
(.96-1.05)\end{array}$ \\
\hline \multicolumn{5}{|l|}{ Enabling Traditional } \\
\hline \# Barriers to Community Health Care & & $\begin{array}{c}.69^{*} \\
(.51-.95)\end{array}$ & & $\begin{array}{c}.64^{* *} \\
(.46-.89)\end{array}$ \\
\hline \multicolumn{5}{|l|}{ Enabling Vulnerable } \\
\hline Disability & & $\begin{array}{c}3.67^{* * *} \\
(1.52-8.88)\end{array}$ & & $\begin{array}{c}3.20^{*} \\
(1.19-8.62)\end{array}$ \\
\hline \multicolumn{5}{|l|}{ Need Traditional } \\
\hline Health Limits Activity & & & $\begin{array}{c}2.03 \\
(.87-4.72)\end{array}$ & $\begin{array}{c}1.81 \\
(.73-4.51)\end{array}$ \\
\hline \# Physical Health Problems & & & $\begin{array}{c}1.10 \\
(.90-1.35)\end{array}$ & $\begin{array}{c}1.26 \\
(.96-1.64)\end{array}$ \\
\hline \multicolumn{5}{|l|}{ Need Vulnerable } \\
\hline Injection Drug User & & & $\begin{array}{c}.36 \\
(.06-2.06)\end{array}$ & $\begin{array}{c}.24 \\
(.03-1.76)\end{array}$ \\
\hline $\mathrm{HIV} / \mathrm{HCV}$ & & & $\begin{array}{c}2.08 \\
(.75-5.82)\end{array}$ & $\begin{array}{c}1.75 \\
(.56-5.49)\end{array}$ \\
\hline$-2 \log$ likelihood & 166.71 & 152.63 & 161.62 & 142.28 \\
\hline Model $\chi^{2}$ & 2.37 & $16.45^{* * *}$ & 7.47 & $26.81^{* *}$ \\
\hline Nagelkerke $\mathrm{R}^{2}$ & .02 & .15 & .07 & .24 \\
\hline \multicolumn{5}{|l|}{ Notes: } \\
\hline \\
\hline \multicolumn{5}{|l|}{ p $<.01$} \\
\hline **** $p<.001$ & & & & \\
\hline
\end{tabular}




\section{Table 6}

Negative Binomial Regression Results Predicting the Number of Ambulatory Outpatient Visits Used by African American Women in the 18 Months After Released from Prison $(\mathrm{N}=161)$

\begin{tabular}{|c|c|c|c|c|}
\hline & $\begin{array}{l}\text { Model 6.1 } \\
\text { I.R.R. } \\
\text { (95\% C.I.) }\end{array}$ & $\begin{array}{l}\frac{\text { Model 6.2 }}{\text { I.R.R. }} \\
\text { (95\% C.I.) }\end{array}$ & $\begin{array}{l}\frac{\text { Model 6.3 }}{\text { I.R.R. }} \\
\text { (95\% C.I.) }\end{array}$ & $\begin{array}{l}\text { Model 6.4 } \\
\text { I.R.R. } \\
\text { (95\% C.I.) }\end{array}$ \\
\hline \multicolumn{5}{|l|}{ Predisposing Vulnerable } \\
\hline Religiosity & $\begin{array}{c}1.01 \\
(.83-1.23)\end{array}$ & & & $\begin{array}{c}1.00 \\
(.82-1.21)\end{array}$ \\
\hline Ethnic Community & $\begin{array}{c}1.10 \\
(.79-1.52)\end{array}$ & & & $\begin{array}{c}1.16 \\
(.82-1.21)\end{array}$ \\
\hline Gendered Racism Scale & $\begin{array}{c}1.02^{* *} \\
(1.01-1.04)\end{array}$ & & & $\begin{array}{c}1.02 * \\
(1.00-1.03)\end{array}$ \\
\hline \multicolumn{5}{|l|}{ Enabling Traditional } \\
\hline \# Barriers to Community Health Care & & $\begin{array}{c}1.01 \\
(.94-1.09)\end{array}$ & & $\begin{array}{c}.96 \\
(.89-1.04)\end{array}$ \\
\hline \multicolumn{5}{|l|}{ Enabling Vulnerable } \\
\hline Disability & & $\begin{array}{c}1.17 \\
(.78-1.76)\end{array}$ & & $\begin{array}{c}.90 \\
(.60-1.36)\end{array}$ \\
\hline \multicolumn{5}{|l|}{ Need Traditional } \\
\hline Health Limits Activity & & & $\begin{array}{c}1.10 \\
(.78-1.56)\end{array}$ & $\begin{array}{c}1.07 \\
(.75-1.53)\end{array}$ \\
\hline \# Physical Health Problems & & & $\begin{array}{c}1.15^{* *} \\
(1.05-1.25)\end{array}$ & $\begin{array}{c}1.12^{*} \\
(1.02-1.23)\end{array}$ \\
\hline \multicolumn{5}{|l|}{ Need Vulnerable } \\
\hline Injection Drug User & & & $\begin{array}{c}1.33 \\
(.73-2.42)\end{array}$ & $\begin{array}{c}1.43 \\
(.79-2.60)\end{array}$ \\
\hline $\mathrm{HIV} / \mathrm{HCV}$ & & & $\begin{array}{c}1.51 \\
(.98-2.32)\end{array}$ & $\begin{array}{c}1.54^{*} \\
(1.00-2.36)\end{array}$ \\
\hline$-2 \log$ likelihood & -486.88 & -491.10 & -481.27 & -478.95 \\
\hline Model $\chi^{2}$ & $9.19^{*}$ & .74 & $20.40^{* * *}$ & $25.05^{* *}$ \\
\hline Nagelkerke $\mathrm{R}^{2}$ & .01 & .01 & .02 & .03 \\
\hline
\end{tabular}

Notes:

p $<.05$;

*** $\mathrm{p}<.01$;

**** $\mathrm{p}<.001$;

I.R.R. = Incidence Rate Ratio, 95\% C.I.=95\% Confidence Interval 